\title{
Types of Abortion and Its Consequences in Dhaka Medical College Hospital
}

\author{
Rokhshana Khatun, ${ }^{1}$ Osman Gani, ${ }^{2}$ Lipika Ghosh, ${ }^{3}$ Mamata Manjari ${ }^{4}$
}

\section{ABSTRACT}

Background \& objective: Among the gynaecological cases admitted in tertiary care hospitals, abortion occupies the highest position. But detailed studies about the pattern of abortion admitted in the hospitals are limited. The present study was intended to find the proportion of abortion cases to total admitted cases and describe the types, clinical presentation and consequences of abortions.

Methods: This study was carried out among a cross-section of abortion patients admitted in the Department of Obstetrics and Gynaecology, Dhaka Medical College Hospital. A total of 100 women admitted with a history of abortion between January and June, 2003 were consecutively included in the study. On admission, blood sample was sent for blood grouping \& cross-matching and estimation of haemoglobin. Additional investigations like routine blood test, TC, DC, urine for R/E were done in septic abortion cases. High vaginal swab was collected from all cases but only in 5 patients, it was possible to carry out culture and sensitivity test. All cases were admitted and followed up to discharge for studying their consequences.

Result: Majority (61\%) of the patients was admitted in their third decade of life. The included cases were predominantly poor $(68 \%)$, Muslim (97\%) and urban residents (78\%). Over half $(54 \%)$ of the patients were illiterate. Sixty percent patients were multipara, $21 \%$ primipara and $19 \%$ nullipara. Two patients were unmarried. One-quarter had previous history of $1-4$ abortions. Of the 100 cases of abortions, over three-quarters (77\%) were of spontaneous abortions and $23 \%$ were of induced abortions. Two-thirds $(66 \%)$ of the cases presented with incomplete abortions, which among others, included incomplete MR (13\%). Septic abortion was $12 \%$; of which $10 \%$ were induced and $2 \%$ spontaneous abortions, complicated to septic abortions. Missed abortion was $10 \%$, inevitable $10 \%$ and threatened $6 \%$. Out of 100 cases, $86 \%$ required operative intervention which included dilatation, evacuation and curettage (95.2\%), subtotal hysterectomy, repair of perforation, hysterotomy and colpotomy. Two threatened abortions cases continued their pregnancy. One threatened abortion, five missed abortion, one septic abortion and six inevitable abortion cases spontaneously expelled their product of conceptus. Seventy-nine patients received whole blood transfusion to compensate for haemorrhage. Over $80 \%$ were discharged from the hospital within 5 days. Complications (except anaemia) of abortion were found in $49 \%$ cases. One case of septic abortion with endotoxic shock and severe anemia died of the disease.

Conclusion: Complications of abortion are preventable if the patients are made aware about the grave consequences of abortion and appropriate health services are extended at field levels.

Key words: Abortion, types of abortion, clinical presentation of abortions and consequences of abortion etc.

\section{Authors' information:}

${ }^{1}$ Dr. Rokhshana Khatun, FCPS (Obstetrics and Gynaecology), Assistant Professor, Colonel Malek medical college, Manikganj.

${ }^{2}$ Dr. Osman Gani, DGO, MCPS (Obstetrics and Gynaecology), Assistant Professor, Colonel Malek medical college, Manikganj.

${ }^{3}$ Dr. Lipika Ghosh, MS (Obstetrics and Gynaecology), Assistant Professor, Colonel Malek medical college, Manikganj.

${ }^{4}$ Dr. Mamata Manjari, FCPS (Obstetrics and Gynaecology), Assistant Professor, Colonel Malek medical college, Manikganj.

Correspondence: Dr. Rokhshana Khatun, Phone: +8801913951960E-mail:drrokhshanakhatun72@gmail.com 


\section{INTRODUCTION:}

The World Health Organization (WHO) defined abortion as the expulsion or extraction of a fetus (embryo) weighing less than $500 \mathrm{gm}$, equivalent to approximately 20-22 weeks gestation. ${ }^{1}$ According to English law, abortion denotes the termination of a pregnancy before twenty-eight weeks' of gestation, that is, before the fetus is viable. ${ }^{2}$ But in our country, the facilities of resuscitation have not yet been developed to the level at which a preterm baby of 28 weeks gestation can survive. Therefore, we still consider the term abortion up to $28^{\text {th }}$ week of pregnancy. The incidence of clinically obvious abortion is $10-15 \% .^{2}$ But loss of very early embryo is certainly higher than this figure. Some studies have estimated the incidence to be $31 \% .^{3}$ Global estimates suggest that every year about 500,000 women die from complications of pregnancy and childbirth, and most of them occur in the developing countries. ${ }^{4}$ WHO has attributed the death of 200,000 women annually to unsafe abortion accounting for 25 to $50 \%$ of all maternal deaths. ${ }^{5}$

Despite nontherapeutic abortion is officially illegal in Bangladesh, this is widely practiced both in urban and rural areas. In Bangladesh, approximately half of the admissions to gynaecology units of major urban hospitals are for complications of abortion. ${ }^{6}$ One-quarter of all pregnancy-related deaths are caused by illegally induced abortion. ${ }^{7}$ of the admitted cases with acute morbidity, $>50 \%$ were admitted due to abortion. ${ }^{8}$

Total patients admitted in Gynaecological unit of Dhaka Medical College Hospital during the year 2002 were 2736; of them, $1300(47.5 \%)$ cases were complications of abortion. However, this does not reflect the actual figure, for the patients coming to the hospital are mostly illiterate and from poor socioeconomic background. Patients from affluent society usually attend the private clinics. Early measure in the management of abortion cases can minimize the rate of death or subsequent complications. In our country, there are publications on septic or induced abortion but a very few works have been done on overall abortion cases admitted in a tertiary care hospital. We, therefore, took interest to work on types of abortion and its consequences in Dhaka Medical College Hospital, which covers all types of abortion in our daily practice. The study aims to 1 ) find the proportion of abortions cases out of total admitted cases, 2) describe different types of abortions with their clinical presentation and consequences and 3) analyze the characteristics of the patients undergoing abortions in relation to their demographics (age, marital status, parity, education, religion, residence, socioeconomic status) and contraceptive behaviour.

\section{METHODS:}

This descriptive study was carried out in the Department of Obstetrics \& Gynecology, Dhaka Medical College Hospital over a period 6 months from January to June 2003. All the cases were admitted and were followed up to discharge for studying their consequences. On admission, blood sample was sent for blood grouping and cross-matching in all cases. Haemoglobin was estimated in 57 cases, who stayed in the hospital for more than one day. Additional investigations like routine blood test, TC, DC, urine for R/E were done in septic abortion cases. High vaginal swab was collected from all cases but only in 5 patients, it was possible to carry out culture and sensitivity test. Plain X-ray abdomen was done in 5 patients to find out perforation of uterus or presence of foreign body or to see the presence of free gas shadow under diaphragm or signs of intestinal obstruction. Four cases of septic abortions were suspected of having urinary tract infection and their urine was sent for culture and sensitivity test. Serum electrolyte determination was possible in few cases of septic abortion only. Ultrasonogram was done in all cases of missed abortions, threatened abortions and in 5 cases of septic abortions.

\section{Treatment of the patients:}

Mode of treatment varied with the types of abortion and condition of the patient, and the complications present at the time of admission and/or developed subsequently. Different modes of treatment given for different abortions are given below: 


\section{Incomplete abortions:}

Hypovolaemic shock with severe per vaginal bleeding was managed with intravenous fluid immediately after admission with inj. oxytocin 20 units $/ 500 \mathrm{ml}$ of dextrose saline. Blood transfusion given as early as possible through another channel. Intravenous inj. hydrocortisone was also used. Evacuation of the uterus was done simultaneously with resuscitation. Inj. ermetrine was used just before curettage. After volume replacement and stoppage of bleeding, if condition of the patients improved, injectable antibiotics were given for 2 days, followed by oral antibiotics. Patients of incomplete abortion with anaemia \& no serious complication was managed as usual. Evacuation \& curettage was done on patients with active per vaginal bleeding and open cervical os immediately after admission. Under deep sedation and with oxytocin drip, evacuation \& curettage was done. Patients who had no active per vaginal bleeding and cervical os was closed, were subjected to $D \& C$ under general anaesthesia. Oxytocin drip was used during operation and inj. ergometrine was used just before curettage. Antibiotics (amoxicillin and metronidazole) were given to all patients from the day of admission with parenteral forms to the day of operation followed by oral antibiotics.

\section{Septic abortions}

Septic abortion cases were initially treated with nothing by mouth, continuous nasogastric suction, intravenous fluid and electrolytes, antibiotics (Inj. Amoxicillin, Gentamycin and Metronidazole). Continuous catheter drainage was done to record the urine output. Antibiotics were modified later on as per report of cultured sensitivity of high vaginal swab or urine culture, if necessary. After resuscitation of the patients, D\&C was done in all cases except two cases who had injury to the uterus.

\section{Missed abortions}

D\&C was done under general anaesthesia with oxytocin drip during operation which continued for 1-2 consecutive days with increasing dose of oxytocin. Patients with partial expulsion of product of conceptus required evacuation \& curettage. Inj. Amoxicillin and Inj. Metronidazole were given to all the patients undergoing $D \& C$ on the day of operation followed by oral antibiotics.

\section{Inevitable abortions}

All patients of inevitable abortions on admission received intravenous fluid and antibiotic injections. Patients who delivered their product of conceptus spontaneously did not require augmentation, but who did not do so required augmentation by oxytocin drip. If placenta was retained, it was removed under general anesthesia. After the day of expulsion of the product of conception, oral antibiotics were started and the patients discharged from hospital with antibiotics, iron and vitamins and other advice.

\section{Threatened abortions}

All patients of threatened abortions were treated in the same manner as was done in cases of inevitable abortion.

\section{Habitual abortions}

Habitual abortion cases were treated as was treated incomplete abortion cases. They were advised to have some investigations done and to attend at OPD with the report of investigations.

\section{RESULTS:}

Over $60 \%$ of the patients were admitted in their third decade of life. Followed by $21 \%$ in $31-40$ years and the rest $18 \%$ in $15-20$ years. The patients were invariably married and ethnically Muslim, predominantly urban residents $(78 \%)$ (mostly slum-dwellers) and generally poor (68\%). Over half $(54 \%)$ of the patients were illiterate. $14 \%$ were primary level educated, $28 \%$ high school and the rest $4 \%$ SSC or higher level educated. Two patients were unmarried (Table I). Spontaneous abortion cases formed the main bulk $(77 \%)$ followed by induced abortion (23\%). All the patients of induced abortion had unwanted pregnancies and of them 13 presented with incomplete MR. The proportion is statistically significant $(p<0.001)$ (Table II). Sixty 
percent patients were multipara, $21 \%$ primipara and $19 \%$ nullipara. Nearly half $(46 \%)$ of the patients ever used contraceptives. One-quarter (24\%) of the patients got admitted within few hours to 1 day, $28 \%$ within 2-5 days and $29 \%$ after 10 days of the onset. Over half (52\%) of the patients had 6-12 weeks of pregnancy, 25\% 13-16 and 23\%>16 weeks of pregnancy. In $75 \%$ cases, there was no history of previous abortion and in $24 \%$ cases there was history of 1-2 previous abortions. More than $80 \%$ stayed in the hospital for $1-5$ days, $12 \% 6-10$ days and $6 \%>10$ days (Table III).

\begin{tabular}{|c|c|c|}
\hline Demographic features & Frequency & Percentage \\
\hline \multicolumn{3}{|l|}{ Age* (years) $^{*}$} \\
\hline $15-20$ & 18 & 18.0 \\
\hline $21-30$ & 61 & 61.0 \\
\hline $31-40$ & 21 & 21.0 \\
\hline \multicolumn{3}{|l|}{ Marital status } \\
\hline Married & 98 & 98.0 \\
\hline Unmarried & 2 & 2.0 \\
\hline \multicolumn{3}{|l|}{ Education } \\
\hline Illiterate & 54 & 54.0 \\
\hline Primary school & 14 & 14.0 \\
\hline High school & 28 & 28.0 \\
\hline Above SSC & 4 & 4.0 \\
\hline \multicolumn{3}{|l|}{ Religion } \\
\hline Muslim & 97 & 97.0 \\
\hline Hindu & 3 & 3.0 \\
\hline \multicolumn{3}{|l|}{ Residence } \\
\hline Rural & 22 & 22.0 \\
\hline Urban & 78 & 78.0 \\
\hline \multicolumn{3}{|l|}{ Socioeconomic status } \\
\hline Below average & 68 & 68.0 \\
\hline Average & 31 & 31.0 \\
\hline Above average & 1 & 1.0 \\
\hline
\end{tabular}

Table II. Major types of abortion $(n=100)$

$\begin{array}{lccc}\text { Majortypes } & \text { Frequency } & \text { Percentage } & \text { p-valuea } \\ \text { Spontaneous } & 77 & 77.0 & <0.001^{*} \\ \text { Induced } & 23 & 23.0 & \end{array}$

${ }^{\mathrm{a} Z}$ test; ${ }^{* * *}$ Highly significant.

\begin{tabular}{|c|c|c|}
\hline $\begin{array}{l}\text { Pregnancy profile \& } \\
\text { abortion history }\end{array}$ & Frequency & Percentage \\
\hline \multicolumn{3}{|l|}{ Parity } \\
\hline Nullipara & 19 & 19.0 \\
\hline Primipara & 21 & 21.0 \\
\hline Multipara & 60 & 60.0 \\
\hline \multicolumn{3}{|l|}{ Use of contraceptives } \\
\hline Ever used & 46 & 46.0 \\
\hline Not used & 54 & 54.0 \\
\hline \multicolumn{3}{|l|}{$\begin{array}{l}\text { Interval between onset of abortion } \\
\text { and admission to hospital }\end{array}$} \\
\hline Few hours to 1 day & 24 & 24.0 \\
\hline 2-5 days & 28 & 28.0 \\
\hline 6-10 days & 9 & 9.0 \\
\hline$>10$ days & 29 & 29.0 \\
\hline Not mentioned & 10 & 10.0 \\
\hline \multicolumn{3}{|l|}{ Duration of pregnancy (weeks) } \\
\hline $6-12$ & 52 & 52.0 \\
\hline $13-16$ & 25 & 25.0 \\
\hline$>16$ & 23 & 23.0 \\
\hline \multicolumn{3}{|l|}{ History of abortion } \\
\hline None & 75 & 75.0 \\
\hline $1-2$ & 24 & 24.0 \\
\hline $3-4$ & 1 & 1.0 \\
\hline \multicolumn{3}{|l|}{ Duration of hospital stay } \\
\hline Few hours (patient expired) & 1 & 1.0 \\
\hline $1-5$ days & 81 & 81.0 \\
\hline 6-10 days & 12 & 12.0 \\
\hline$>10$ days & 6 & 6.0 \\
\hline
\end{tabular}

Table-IV shows the detailed classification of abortion cases. Two-thirds (66\%) of the cases presented with incomplete abortions, which among others, included incomplete MR (13\%). Septic abortion was $12 \%$; of which 10 were induced and 2 were spontaneous, later turned into septic abortions. Missed abortion was $10 \%$, inevitable and threatened each was $6 \%$. In terms of mode of presentation, majority (92\%) of patients presented with per vaginal bleeding (92\%) and $56 \%$ with pain in the abdomen. Various complications (from mild, negligible to severe life-threatening complications) developed. In $60 \%$ of the cases cervical os was open, in $34 \%$ cases it was closed and in rest $6 \%$ cases per 
vaginal examination was not done. Over $90 \%$ had mild to moderate anaemia. Rest of the patients had different types of complications, like shock, haemorrhage, infection, injury to the uterus or cervix and incomplete D\&C cases with PID (Table IV).

\begin{tabular}{|c|c|c|}
\hline Abortion-related profile & requency & Percentage \\
\hline \multicolumn{3}{|l|}{ Classification of abortion $(n=100)$} \\
\hline Incomplete & 66 & 66.0 \\
\hline Septic & 12 & 12.0 \\
\hline Missed & 10 & 10.0 \\
\hline Inevitable & 6 & 6.0 \\
\hline Threatened & 6 & 6.0 \\
\hline \multicolumn{3}{|l|}{ Clinical presentation of the patients $\left(n=100^{*}\right)$} \\
\hline Per vaginal bleeding (mild to severe) & 92 & 92.0 \\
\hline Pain in the abdomen (mild to severe) & 56 & 56.0 \\
\hline Fever & 11 & 11.0 \\
\hline Foul smelling per vaginal discharge & 10 & 10.0 \\
\hline Abdominal distension & 4 & 4.0 \\
\hline \multicolumn{3}{|l|}{ Condition of the cervix $(n=100)$} \\
\hline Cervical os open & 60 & 60.0 \\
\hline Cervical os closed & 34 & 34.0 \\
\hline Per vaginal examination not done & 6 & 6.0 \\
\hline \multicolumn{3}{|l|}{ Consequences of abortion ( $n=100 *$ ) } \\
\hline Shock & 11 & 11.0 \\
\hline Haemorrhagic & 10 & 10.0 \\
\hline Endotoxic & 1 & 1.0 \\
\hline Haemorrhage & 14 & 14.0 \\
\hline Attended with severe per vaginal bleeding & 10 & 10.0 \\
\hline Injury to the uterus and cervix (induced abortion) & n) 2 & 2.0 \\
\hline Incomplete D\&C & 2 & 2.0 \\
\hline Infection & 11 & 11.0 \\
\hline Evidence of PID at the time of discharge & 2 & 2.0 \\
\hline Anaemia (mild to moderate) & 91 & 91.0 \\
\hline Death & 1 & 1.0 \\
\hline \multicolumn{3}{|l|}{ Treatment $(n=100)$} \\
\hline Conservative treatment & 14 & 14.0 \\
\hline Operative treatment & 86 & 86.0 \\
\hline Types of operative treatment $(n=86)$ & 82 & 82.0 \\
\hline Dilatation, evacuation and curettage & 82 & 95.2 \\
\hline Subtotal hysterectomy & 1 & 1.2 \\
\hline Repair of perforation & 1 & 1.2 \\
\hline Colpotomy & 1 & 1.2 \\
\hline Hysterotomy & 1 & 1.2 \\
\hline
\end{tabular}

Majority (86\%) of the cases required operative intervention which included dilatation, evacuation and curettage (95.2\%), subtotal hysterectomy $(1.2 \%)$, repair of perforation $(1.2 \%)$ and hysterotomy $(1.2 \%)$. In addition to $D \& C$, one patient needed colpotomy. Two threatened abortions cases continued their pregnancy. One threatened abortion, five missed abortion, one septic abortion and six inevitable abortion cases spontaneously expelled their product of conceptus (Table IV). Out of 100 cases, $13 \%$ had $\mathrm{Hb}$ between 3-40 gm/dl, 21\% 40-50 gm/dl and 23\% $50 \mathrm{gm} / \mathrm{dl}$ or more before deciding for blood transfusion. Blood transfusion was required in 79\% cases (Table V).

\begin{tabular}{|c|c|c|}
\hline $\begin{array}{l}\text { Hb status and need of } \\
\text { blood transfusion }\end{array}$ & Frequency & Percentage \\
\hline \multicolumn{3}{|c|}{$\begin{array}{l}\text { Hemoglobin status of the } \\
\text { patients before treatment }\end{array}$} \\
\hline $31-40$ & 13 & 13.0 \\
\hline $40-50$ & 21 & 21.0 \\
\hline$\geq 50$ & 23 & 23.0 \\
\hline Not done & 43 & 43.0 \\
\hline \multicolumn{3}{|l|}{ Blood transfusion } \\
\hline Required & 79 & 79.0 \\
\hline Not required & 21 & 21.0 \\
\hline
\end{tabular}

\section{DISCUSSION:}

Over the six months period of this study, it was found that abortion comprises more than $50 \%$ of all gynaecological admissions in Dhaka Medical College Hospital, though the annual figure is a little low $(47.5 \%)$. This agrees with earlier reports that abortion related cases constitute a large share of the total gynaecological admissions in the teaching hospitals in Bangladesh. ${ }^{7}$ Seventy-seven percent of all the cases were spontaneous and $23 \%$ induced abortion. About two-thirds (66\%) of the abortion cases were incomplete abortion which is almost comparable to an earlier report of $74 \%$ incomplete abortion from sylhet MAG Osmani Medical College Hospital. ${ }^{9}$ Among the 
incomplete abortion, one patient had habitual abortion. Two patients were unmarried. Septic abortion in this series was 12 percent which also reflects a low incidence of sepsis compared to a previous report by Nilufar in 1990 (14.5\%). ${ }^{10}$ It indicates a changing pattern of inducing abortions including more use of antibiotics by the untrained abortionists.

Of the 66 patients of incomplete abortions, ten patients came with hypovolaemic shock with severe per vaginal bleeding. Intravenous fluid was started immediately after admission with Inj. Oxytocin 20 units $/ 500 \mathrm{ml}$. Blood transfusion was given as early as possible through another channel. Intravenous Inj. Hydrocortisone was used. Evacuation of the uterus was done simultaneously with resuscitation. Inj. Ermetrine was used just before curettage. After volume replacement and stoppage of bleeding, condition of the patients improved. Injectable antibiotics were given for 2 days, followed by oral antibiotics. Ten patients came with excessive per vaginal bleeding. They were treated as above. One patient developed excessive per vaginal bleeding during evacuation and curettage. Two units of whole blood was transfused during the operation till the patient became stable. Rest of the patients of incomplete abortion had no serious complication with anaemia being the common feature. They were treated as usual. Out of 66 incomplete abortion patients, 13 were admitted due to incomplete menstrual regulation.

Ten percent cases of this study were of missed abortion, six percent inevitable and six percent threatened abortions. The overall incidence of clinically recognizable spontaneous abortion before 20 weeks of gestation was $12 \%$. To determine the cause of spontaneous abortion, patient's previous obstetric history is very important. In primigravida and women with a history of consistently successful pregnancies, the incidence of abortion is low, whereas, women with unsuccessful histories of completing pregnancies bear a much higher risk of abortion in the next pregnancy $(24 \%)$ as well. More than half (52\%) of the patients in this study were seen at the first trimester and most of them had spontaneous abortions. Those patients with induced abortion had pregnancy mostly advanced to second trimester. One study showed that about half of the abortions were done in young, unmarried women in the developed countries but in the developing countries, abortion is most common among married women with 2 or more children. ${ }^{11}$ Twelve cases in this series were septic abortions-10 induced and 2 spontaneous, later complicated to septic abortion. In spite of restriction by law, induced illegal abortion is taking place in large numbers in our country. A review article published in 1993 characterized induced abortion in Latin America as an epidemic with 3-5 million performed each year. ${ }^{12}$ Another study estimated that 550,000 women are hospitalized each year as a result of complications from induced abortion in Brazil, Chile, Columbia, the Dominican Republic, Mexico and Peru. ${ }^{13}$ The procedure is adopted either by the women themselves in secret as done by the unskilled abortionists which constitute the risk of life and health. In this series, all 10 cases of induced abortions were carried out by the abortionists who used sticks to bring about the termination of the pregnancy. One previous study showed that nearly half of the complicated abortions were induced by inserting a foreign body, such as stick or root into the uterus and leaving these till either abortion or complication ensued. ${ }^{6}$ In the present study, one patient admitted with septic abortion with complications of endotoxic shock with severe anaemia expired within four hours of admission. However, this does not reflect the overall death rate due to abortion, because most of the patients in this series were cases of spontaneous abortion with minimum complication. In a study by Nilufar, mortality rate was much higher (10\%). ${ }^{10}$ In this series, two unmarried patients attended with abortion, which does not seem to reflect the actual picture of abortion in Dhaka city, for most unmarried cases of abortion attend the private clinics or chambers in order to maintain secrecy. 
Majority (91\%) of the patients suffered from mild to moderate degree of anaemia observed at the time of discharge from hospital. Apart from anaemia, about half (49\%) of the patients in this series had some form of complications. In this study, it has been observed that though the incidence of spontaneous abortion is much higher, their management was not so complicated or time consuming. Most of the cases could be discharged within 48 hours of their admission after a simple operation like D\&C with a short course of antibiotic therapy. Except some cases of spontaneous abortion, all cases were managed successfully without any complication. Two cases of spontaneous abortions attended with septic complication, 10 patients attended with hypovolaemic shock due to haemorrhage. They recovered after immediate blood transfusion.

Management of septic abortions was not so simple. These patients had to stay in the hospital for a longer period of time. Their management constituted whole blood transfusion, long time antibiotic therapy after high vaginal swab culture and sensitivity test. One patient of septic abortion in this series required subtotal hysterectomy and another required repair of perforation due to injury to the uterus. Two patients had signs of PID at the time of discharge.

Thus, the septic abortion, a preventable condition, is still a hazard to our health service affecting not only the individual patient or their family, rather the whole nation. In this study, $46 \%$ of the patients had used contraceptives at some time of their life, which may be compared to contraceptive prevalence in our country (about $45 \%$ of eligible couples). The number of unintended pregnancy was $23 \%$; of them 9 patients were irregular user of contraceptive pills or condom and 14 patients did not at all use any contraceptives. In a study carried out in Peru during the period of 1991-1992. Out of 1093 women, 20 percent had unintended pregnancy. Among them, 35\% were contraceptive non-user and $26 \%$ were due to failure of traditional methods, $2 \%$ had an unintended pregnancy while using modern methods and 4\% shortly after discontinuing the use of modern methods. ${ }^{14}$ In developed countries like Russia, Japan, Eastern European countries, Israel and the United States, the highest total legal abortions range from 1 to $>5$ abortions per woman during their reproductive years. Developing countries from where reliable data are unavailable (South Korea, China, Cuba and Singapore), have 1-2 abortions per woman of child-bearing age. ${ }^{15}$

In Bangladesh, the rate of unplanned pregnancy is $50 \%$ and unwanted pregnancy rate is $25 \%$. So, unsafe abortion continues to cause an increased rate of maternal morbidity and mortality. Contraceptive use is the first line of defense against unwanted pregnancy and illegal abortion. Therefore, safe and effective fertility control, including abortion performed by adequately trained health workers in both in and outpatient facilities, might be the most appropriate first step in preventing pregnancy-related deaths in Bangladesh. ${ }^{16}$ Like any other scientific studies, the present study was not without limitations. Before going to conclude the study the limitations that deserve mention should be highlighted:

\section{Limitations:}

1. All the patients had to be managed in the hospital with limited facilities of investigation and management.

2. Our hospital facilities are limited for all needed laboratory investigations. So, many vital investigations which were urgently needed for more seriously ill patients could not be carried out.

3. CVP or arterial blood $\mathrm{pH}$ could not be determined in any patients.

4. $\beta$-hCG and histopathology or autopsy of product of conceptus or serological tests were not done routinely.

\section{CONCLUSION:}

Abortion is a very common gynaecological problem in Bangladesh with spontaneous abortion 
being the predominant. The sufferers of abortion cases were generally married, multipara, illiterate, predominantly urban residents and belonged to poor socioeconomic class. As about half of the gynaecological patients are abortion cases, their management greatly hampers the admission and management of other gynaecological patients in our hospitals with limited bed and other resources. Though the national family planning programme is providing contraceptive services throughout the country, thousands of couples have yet to be reached to protect them from unwanted pregnancy. To get rid of the unwanted pregnancies, women often seek abortion from untrained providers who contribute greatly to maternal mortality and morbidity. Thus, every preventive measure should be taken in order to reduce the incidence of abortion and its complications.

\section{REFERENCES:}

1. Keith ED. Miscarriage, ectopic pregnancy and trophoblastic disease. In: Dewhurst's textbook of obstetrics and gynaecology for postgraduates. $6^{\text {th }}$ ed. Blackwell Science Ltd., 1991: 61-75.

2. Jeffcoate N. Abortion. In: Tindall VR, editor. Jeffcoate's principles of gynaecology. $5^{\text {th }}$ ed. London: Butterworth and Co., Ltd., 1987: 191-211.

3. Wilcox AJ, Weinberg $C R$, O'Connor JF, Baird DD, Schlatterer JP, Canfield RE, et al. Incidence of early pregnancy loss. N Engl Med 1988;319:189-94.

4. Lis kin LS. Maternal morbidity in developing countries: a review and comments. Int Obstet Gynaecol 1992;37:77-87.

5. Paxman M, Rizo A, Brown L, Benson L. The clandestine epidemic: the practice of unsafe abortion in Latin America. Stud Fam Plan 1993;24:205-26.

6. Measham AR, Obaidullah M, Rosenberg MJ, Rochat RW, Khan AR, Labeen $S$. Complications from induced abortion in Bangladesh related to types of practitioners and methods and impact on fertility. Lancet 1981; 1:199-202.

7. Khan AR, Begum SF, Covington DL, Jano_:vitz B, James $S$, Potts M. Risks and costs of illegally induced abortion in Bangladesh. J Biosoc Sci 1984; 16:89-98.

8. Parveen F, Rahman D. Maternal morbidity as assessed from hospital indoor admissions. Bangladesh J Obstet Gynaecol 1995; 10:73-82.
9. Akhter R. Types of abortion and its consequences: a report of 100 cases $\mathrm{m}$ Sylhet M.A.G. Osmani Medical College Hospital [dissertation]. Dhaka: Bangladesh College of Physicians and Surgeons, 1997.

10. Nilufar S. Pathogenesis of septic abortion: a report of 100 cases in Dhaka Medical College Hospital [dissertation]. Dhaka: Bangladesh College of Physicians and Surgeons, 1990.

11. Henshaw SK. Induced abortion: world review. Fam Plan Perspect 1990;22:76-89.

12. Singh S, Sedgh $\mathrm{G}$. The relationship of abortion to trends in contraception and fertility in Brazil, Columbia and Mexico. Intern F am Plan Perspect 1997;23:4-14.

13. Singh S, Wulf D. Estimated level of induced abortion in six Latin American countries. Intern Fam Plan Perspect 1994;20:4-13.

14. Mensch BS, Arends-Kuenning M, Jain A, Garate MR. Avoiding unintended pregnancy in Peru: does the quality of family planning services matter? Intern Fam Plan Perspect 1997;23:21-7.

15. Frejka T. Induced abortion and fertility. Intern Fam Plan Perspect 1985;11:125-9.

16. Rochat RW, Jabeen S, Rosenberg MJ, Measham AR, Khan $A R$, Obaidullah $M$, et al. Maternal and abortion related deaths m Bangladesh, 1978-1979. Int J Gynaec Obstet 1981;19:1. 